Seiten 119 und 134 "versteckt". Dies soll den Wert des Katalogteiles aber nicht schmälern - er ist z.B. eine Fundgrube für Informationen über die bekannte Verbreitung mitteleuropäischer Arten vom Osten Europas bis in den fernsten Osten der Paläarktis.

Auf Seite 226 beginnt das umfangreiche Literaturverzeichnis. Bis Seite 400 erstrecken sich die kyrillischen Autorennamen, die alle Zitate der Autoren der SU enthalten, unabhängig davon, ob sie in lateinischer, kyrillischer oder anderer Schrift erschienen waren. Das kyrillische Alphabet erschwerte mir das Finden z.B. der baltischen Autoren. Die Titel aller Zitate sind auch als englische Übersetzung vorhanden, leider aber nicht die Zeitschriften- und Verlagsangaben. Von Seite 400 bis 415 folgen Zitate mit Autoren in lateinischer Schrift (von AUSSERER bis ZABKA). Der 32seitige Index wurde separat nachgeliefert. Er erleichtert die Suche nach den Arten erheblich, da er Arten-, Gattungs- und Familienbezeichnung einschließlich der Synonyme enthält.

Zusammenfassend: ein wichtiges Nachschlagewerk.

Theo Blick

\title{
NIEUWSBRIEF SPINED (NIEUWSBRIEF van de SPInnenwerkgroep
} NEDerland). Leiden. Niederländisch, zum Teil mit englischen abstracts. ISSN 0926-0781

Zusammenstellung und Korrespondenzadresse: P.J. van Helsdingen, Natuurhistorisch Museum, Raamsteg 2, NL-2311 PL Leiden, Nederland, E-mail: helsdingen@nnm.nl

Erscheinungsweise: unregelmäßig, Preis pro aktuelle Ausgabe (für $D$ ): 5 DM (Banknote)

Alle Ausgaben lagen vor: 1983: No 1, 1984: No 2, 1985: № 3, 1986: No 4, 1988: No 5, 1989: No 6, 1993: No 7, 1995: № 8 \& 9, 1996: No 10, 1997: No 11.

Die Hefte umfassen zwischen 4 und 22 Seiten (DIN A4). Beispielhaft seien die Titel der aktuellen Ausgabe (März 1997) und ausgewählte aus den anderen Heften genannt (Ergänzungen/Übersetzungen in "[]"). 


\section{No 11 (März 1997):}

PRINSEN, J.D.: Eperigone eschatologica (CROSBY, 1924) (Araneae: Linyphiidae), een nieuwe spin in Nederlandse kassen. - S. 1-3

SPOEK, G.L.: Bodembewonende spinnen, hooiwagens [Weberknechte] en bastaardschkorpioenen [Pseudoskorpione] in het hoogveenreservaat het Bargerveen en in het Oosterbos. - S. 3-4

HELSDINGEN, P.J. van: Achtergrondsgegevens [Übersicht] van de Theridiidae uit Nederland en de omringende landen. - S. 5-21

NOORDAM, A.P.: Enkele correcties op de soortenlijst van de spinnen van Nederland. S. 21-22

No 1 (1983) bis No 10 (1996) (Auswahl):

HELSDINGEN, P.J. van (1983): Exkursie Kortenhof 1982 [incl. Unterscheidung Agyneta ramosa/subtilis-Weibchen]. - No 1:2-4

HELSDINGEN, P.J. van (1985): Porrhomma: een groep vol problemen. - No 3:3-5

HELSDINGEN, P.J. van (1986): Uloborus plumipes LUCAS in ons land. - No 4:3-4

HELSDINGEN, P.J. van (1988): Segestria-soorten in Nederland. - No 5:1

HELSDINGEN, P.J. van (1993): Lijst van in Nederland actueel en mogelijk voorkomende spinnen. - No 7:2-17

HELSDINGEN, P.J. van (1995): Meer gegevens over Neriene hammeni. - No 8:6

HELSDINGEN, P.J. van (1995): Ceraticelus bulbosus (EMERTON, 1882) (Araneae, Linyphiidae), een ouder synoniem van Ceraticelus sibiricus ESKOV, 1987, in Nederland gevonden. - No 9:1-4

HELSDINGEN, P.J. van (1995): Een stukje tropen in Nederland [Coleosoma floridana (Theridiidae)]. - No 9:4-6

HELSDINGEN, P.J. van (1996): Nieuwe soorten voor Nederland. - No 10:7-8

KOOMEN, P. (1988): Psilochorus simoni (BERLAND, 1911) doet Leiden aan. - No 5:17

PRINSEN, J.D. (1996): Theridion uhligi MARTIN, 1974(Araneae: Theridiidae), een zeldzame kogelspin van heideterreinen. - No 10:4-7

ROELOFS-DITTERS, E. (1996): Zora pardalis SIMON op de Strabrechtse Heide. - No 10:1-2

Der holländische Text ist für Deutschsprachige zum großen Teil ohne Wörterbuch zu verstehen. Englische abstracts für alle Artikel wären wünschenswert. Die Mehrzahl der Arbeiten stammt von van HELSDINGEN selbst. Neben der Spinnenliste der Niederlande finden sich in der Zeitschrift weitere interessante Themen (s.o.). Insgesamt ist das Periodikum für Arachnologen/innen, die über die deutschen Grenzen hinaussehen möchten, als Lektüre zu empfehlen. 